\title{
The Exploitation of Vehicle-to-Grid Function for Power Quality Improvement in a Smart Grid
}

\author{
Morris Brenna, Member, IEEE, Federica Foiadelli, Member, IEEE, and Michela Longo
}

$\mathbf{T}$ HE transition of a modern electric distribution network toward smart grids, the efficient integration of the growing electric energy production from renewable sources, and the gradual transformation of the energy final consumer into a prosumer make the themes of power quality (PQ) and energy storage a real current problem.

In fact, on one hand, there is a need for a more sustainable system that leads to an always more complex energy network composed of many active loads and distributed generators that, in many cases, are not programmable and displaceable [1][3]. On the other hand, such a system requires a high safety and continuity level in order to guarantee its stability, whereas many studies with regard to main network problems show that the electric distribution grids are still interested by considerable disturbances that affect the quality of the power delivered to the users [4], [5].

The big challenge will be the real exploitation of the energy resources distributed into a network to improve the quality of power, and the scientific international literature intensely discusses on it. In such context, this paper aims to provide a possible solution to some common and dangerous PQ problems and voltage sags, considering the large diffusion of electric vehicles (EVs). In fact, the European Union (EU) has pledged a huge expansion of infrastructure for EVs with binding targets to multiply the number of Europe's charging stations, which is part of a new strategy to kick-start Europe's low-carbon

Manuscript received October 9, 2013; revised January 17, 2014; accepted March 1, 2014. Date of publication May 19, 2014; date of current version September 26, 2014. The Associate Editor for this paper was L. Li.

The authors are with Politecnico di Milano-Department of Energy, 20156 Milan, Italy (e-mail: morris.brenna@polimi.it; federica.foiadelli@polimi.it; michela.longo@polimi.it).

Color versions of one or more of the figures in this paper are available online. automotive industry [6]-[9], that could help the EU targets on $\mathrm{CO}_{2}$ emission reduction. The proposal states that a minimum number of electric charging units is needed in each EU member state by 2020 , and at least $10 \%$ of these should be publicly accessible. The number of required electric charging points varies according to each country's production plans.

Proven that many new recharging stations will be provided around cities, it is necessary to evaluate if the so-called vehicleto-grid (V2G) solution can be really a challenge in the smart grid concept. Scientific literature contains many examples of research works studying the $\mathrm{V} 2 \mathrm{G}$ function, which is mostly based on the ability of $\mathrm{V} 2 \mathrm{G}$ to balance the demands of the grid with the available supply, the cost returns of V2G operations, and the integration of renewable energy into the V2G concept [10]-[15].

A smart interaction between vehicles and an electric grid is only interesting if it brings advantages to both realities. Therefore, it is necessary to evaluate different elements (PQ events, the grid interconnection degree, the EVs' number and storage capacity, and load islands) in order to find where the V2G application is not only feasible but also convenient.

In particular, Section II estimates the most probable events in which the residual voltage values are suitable for a V2G compensation referring to different grid interconnection degrees. Section III performs an energy analysis that correlates the storage capacity available (in terms of the battery capacity and number of connected vehicles) with the nondelivered energy (in terms of the deepness and duration of voltage sags). Section IV proposes the electric model and the interaction between an electric grid and vehicles defining the different load islands. For these scenarios, the probable number of connected vehicles is determined.

The results of the previous analysis are combined for the final analysis in Section V in order to determine the areas of convenience of the proposed solution.

\section{Distribution of the Voltage Dips in Italy}

This section presents a deep analysis of the distribution of the voltage sags that occurred on the Italian electric network in order to determine the most probable events that can be compensated for with the batteries onboard the EVs.

The data used for this analysis, which are recorded by the national PQ monitoring system QuEEN [16] on the 400 most representative Italian high-voltage/medium-voltage substations, refer to the voltage dips that occurred in Italy during the year 2012, and they are gathered in four groups 


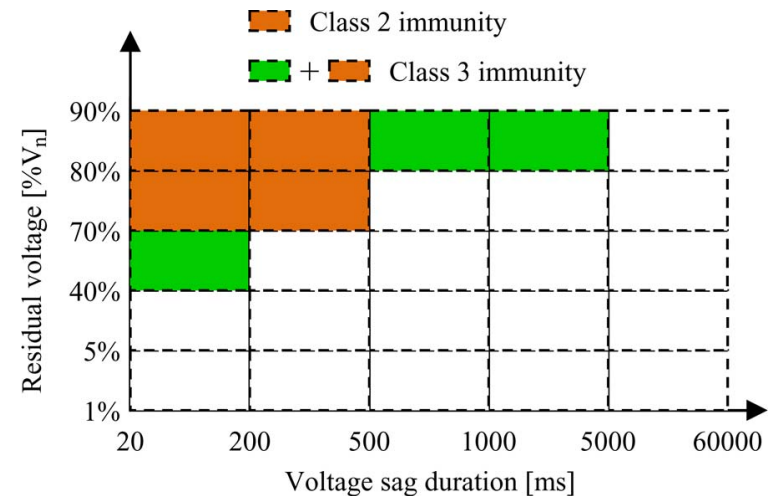

Fig. 1. Classification of the voltage dips according to the standard EN-50160.

TABLE I

Voltage Dips for the High Interconnected Industrial AREA

\begin{tabular}{ccc}
\hline \hline $\begin{array}{c}\text { Residual } \\
\text { Voltage [\%] }\end{array}$ & Number of Voltage dips & Average duration [ms] \\
\hline $90>\mathrm{u} \geq 80$ & 880 & 97 \\
$80>\mathrm{u} \geq 70$ & 290 & 117 \\
$70>\mathrm{u} \geq 40$ & 486 & 126 \\
$40>\mathrm{u} \geq 5$ & 174 & 172 \\
$5>\mathrm{u} \geq 1$ & 3 & 110 \\
\hline
\end{tabular}

corresponding to four different territorial zones. The choice of the following four areas has been performed because they represent different grid interconnection degrees with a widearea voltage regulation [17]:

1) high interconnected industrial area;

2) low interconnected industrial area;

3) low interconnected rural area;

4) quasi-isolated area.

According to the European standard EN 50160 [18], the voltage dips are classified based on their duration and residual voltage. The immunity curves for equipment belonging to classes 2 and 3 are reported in Fig. 1, following the European standards EN 61000-4-11 [19] and EN 61000-4-34 [20]. Class 2 is normally composed of domestic and office electric appliances connected to the public distribution network, whereas class 3 appliances are related to the industrial environment.

Considering a set of events (sags) that are characterized by a particular residual voltage with a certain duration, equipment is considered immune to voltage dips if its values overcome the curves of immunity (see the cells in Fig. 1).

The definition of the immunity areas is important in order to ignore those network events that are not dangerous for the correct working of the appliances. Consequently, from the total number of voltage dips $N$, it is necessary to identify the number of voltage dips that are dangerous for class 2 appliances, i.e., $N_{2}$, and for class 3 appliances, i.e., $N_{3}$. Referring to Fig. $1, N_{2}$ is the number of voltage dips inside the white and green cells, whereas $N_{3}$ is that only inside the white cells.

\section{A. High Interconnected Industrial Area}

Table I reports the collected data classified for the residual voltage according to the classification reported in the standard EN-50160.
TABLE II

Voltage Dips For THE LOW INTERCONNECTED INDUSTRIAL AREA

\begin{tabular}{ccc}
\hline \hline $\begin{array}{c}\text { Residual } \\
\text { Voltage [\%] }\end{array}$ & Number of Voltage dips & Average duration [ms] \\
\hline $90>\mathrm{u} \geq 80$ & 1173 & 141 \\
$80>\mathrm{u} \geq 70$ & 539 & 155 \\
$70>\mathrm{u} \geq 40$ & 573 & 175 \\
$40>\mathrm{u} \geq 5$ & 220 & 165 \\
$5>\mathrm{u} \geq 1$ & 0 & 0 \\
\hline
\end{tabular}

TABLE III

Voltage Dips For the LOW InTERCONNECTED RuRAL AREA

\begin{tabular}{ccc}
\hline \hline $\begin{array}{c}\text { Residual } \\
\text { Voltage [\%] }\end{array}$ & Number of Voltage dips & Average duration [ms] \\
\hline $90>\mathrm{u} \geq 80$ & 1854 & 322 \\
$80>\mathrm{u} \geq 70$ & 598 & 158 \\
$70>\mathrm{u} \geq 40$ & 985 & 180 \\
$40>\mathrm{u} \geq 5$ & 293 & 229 \\
$5>\mathrm{u} \geq 1$ & 3 & 193 \\
\hline
\end{tabular}

TABLE IV

VOLTAGE DiPS FOR THE QUASI-ISOLATED AREA

\begin{tabular}{ccc}
\hline \hline $\begin{array}{c}\text { Residual } \\
\text { Voltage [\%] }\end{array}$ & Number of Voltage dips & Average duration [ms] \\
\hline $90>\mathrm{u} \geq 80$ & 2143 & 176 \\
$80>\mathrm{u} \geq 70$ & 1106 & 203 \\
$70>\mathrm{u} \geq 40$ & 1349 & 222 \\
$40>\mathrm{u} \geq 5$ & 605 & 195 \\
$5>\mathrm{u} \geq 1$ & 12 & 267 \\
\hline
\end{tabular}

From Table I, it is possible to deduce that $37.1 \%\left(N_{2}=\right.$ $680)$ of the total voltage dips $(N=1833)$ are dangerous for the devices of class 2 , whereas $12.1 \%\left(N_{3}=221\right)$ cause the malfunctioning of class 3 appliances.

\section{B. Low Interconnected Industrial Area}

Table II reports the collected data classified for the residual voltage according to the classification reported in the standard EN-50160.

From Table II, it is possible to deduce that $34.7 \%\left(N_{2}=\right.$ $872)$ of the total voltage dips $(N=2507)$ are dangerous for the devices of class 2 , whereas $14.8 \%\left(N_{3}=372\right)$ cause the malfunctioning of class 3 appliances.

\section{Low Interconnected Rural Area}

Table III reports the collected data classified for the residual voltage according to the classification reported in the standard EN-50160.

From Table III, it is possible to deduce that $36.3 \%\left(N_{2}=\right.$ $1358)$ of the total voltage dips $(N=3733)$ are dangerous for the devices of class 2 , whereas $14.9 \%\left(N_{3}=556\right)$ cause the malfunctioning of class 3 appliances.

\section{Quasi-Isolated Area}

Table IV reports the collected data classified for the residual voltage according to the classification reported in the standard EN-50160.

From Table IV, it is possible to deduce that $41.1 \%\left(N_{2}=\right.$ $2142)$ of the total voltage dips $(N=5212)$ are dangerous for 


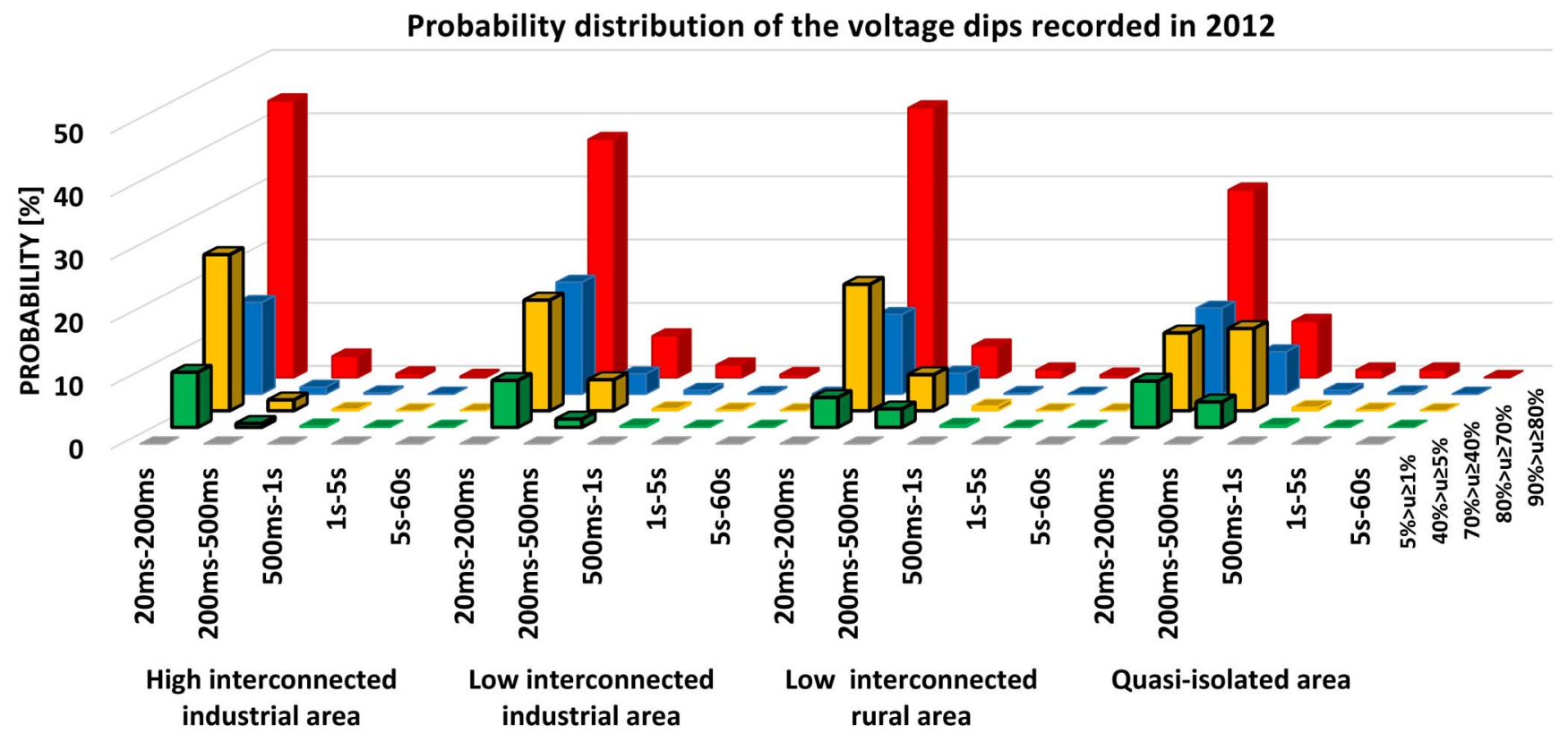

Fig. 2. Voltage dips' distribution in relation to their deepness and duration for the four considered zones.

the devices of class 2 , whereas $26.3 \%\left(N_{3}=1373\right)$ cause the malfunctioning of class 3 appliances.

From the previously mentioned results reported, it is possible to observe that the number of voltage dips is very different depending on the considered zone. In fact, different grid interconnection degrees mean influence on the quality of the delivered power.

A probabilistic analysis of the collected data has been performed to identify the most probable events that are suitable for V2G compensation.

The results are summarized in Fig. 2, where it is possible to observe the voltage dips' distribution in relation to their deepness and duration for the four considered areas.

The first analysis of the probability distribution shows that the most probable events have a short duration (20-200 ms), with a deepness between $90 \%$ and $80 \%$, but they are not dangerous for both classes 2 and 3 devices; therefore, they will not be considered in the following.

Instead, it is important to identify those events that are dangerous for class 2 and/or class 3 appliances and that also have a significant probability to become interesting for their compensation with a V2G application. Therefore, the dips with a residual voltage between 5\% and 70\% and a duration of up to $500 \mathrm{~ms}$ (the bold line bars in Fig. 2) will be considered in the following.

Finally, it is possible to note that the different grid interconnection degrees strongly influence both the total number of events and their distribution. For example, a quasi-isolated area presents not only a high number of voltage dips but also events characterized by a higher average duration.

\section{TheOretical (ENERGy) AnAlysis}

In order to understand the ability of an EV to carry out ancillary services for electric distribution grids, which is called V2G functions, it is necessary to develop a preliminary theoretical analysis. As a result, performance indicators are defined to compare the different cases that will be discussed in the following.

The variables, parameters, and quantities used in this analysis are the following:

- $d_{s}$ : the deepness of the voltage sag;

- $T_{s}$ : the duration of the voltage sag;

- $T_{r E}$ : the duration of the V2G power flow;

- $V_{n}$ : the rated voltage of the primary distribution network;

- $V_{r}$ : the residual voltage during a sag or an interruption;

- $V_{r c}$ : the compensated voltage during a sag or an interruption;

- $P_{c}$ : the compensation power supplied by a $\mathrm{V} 2 \mathrm{G}$ recharging station during a sag or an interruption;

- $E_{c}$ : the compensation energy supplied by a V2G recharging station during a sag or an interruption;

- $P_{D}$ : the power of the primary distribution network that supplies the district in which EVs are connected;

- $P_{\mathrm{CS}}$ : the EV charging power available in the charging station;

- $P_{d \mathrm{EV}}$ : the power drawn from an EV;

- $N V_{c}$ : the number of EVs necessary for sag or interruption compensation;

- $T_{C}$ : the charging time;

- $E_{\mathrm{EV}}$ : the energy stored in the battery onboard an EV;

- $E_{\mathrm{EV} 2 G}$ : the energy drawn from an EV for compensating a sag or an interruption;

- $\mathrm{SOC}_{i}$ : the initial state of charge (SOC) of an EV.

In case of an event such as a voltage sag or an interruption in the primary distribution network, residual voltage $V_{r}$ is

$$
V_{r}=\left(1-d_{s}\right) \cdot V_{n}
$$

Since the aim of a compensation system is to supply an electric load without causing malfunctioning and without minimizing the compensation energy and power, it is assumed that 
the residual voltage after compensation is equal to $90 \%$ of the rated voltage; therefore

$$
V_{r c}=0.9 \cdot V_{n}
$$

At this point, it is possible to calculate the compensating power and energy, i.e., the power and energy that the set of EVs has to give back to the grid in order to compensate for sags or interruptions, as:

$$
\begin{aligned}
& P_{c}=P_{D} \cdot \frac{\left(V_{r c}-V_{r}\right)}{V_{n}}=P_{D} \cdot\left(d_{s}-0.1\right) \\
& E_{c}=P_{c} \cdot T_{s} .
\end{aligned}
$$

Because the most critical parameter is the electric power, the number of EVs necessary for the compensation will be given by the ratio between compensating power $P_{c}$ and charging power $P_{\mathrm{CS}}$. Assuming that the discharging power during the $\mathrm{V} 2 \mathrm{G}$ function is equal to the charging power of the station, $N V_{c}$ is

$$
N V_{c}=\frac{P_{c}}{P_{\mathrm{CS}}}=\frac{P_{D} \cdot\left(d_{s}-0.1\right)}{P_{\mathrm{CS}}} .
$$

$N V_{c}$ represents the first indicator that links the power of a charging station to the compensating power for a particular district or area.

Once the minimum number of EVs is determined, it is possible to obtain the amount of energy requested by each vehicle and given back to the network as

$$
E_{\mathrm{EV} 2 G}=\frac{E_{C}}{N V_{c}}=\frac{P_{C} \cdot T_{s}}{\frac{P_{C}}{P_{\mathrm{CS}}}}=P_{\mathrm{CS}} \cdot T_{s} .
$$

As it is possible to note, this value is proportional to the charging power and the duration of the event that have to be compensated for. However, $E_{\mathrm{EV} 2 G}$ is not useful as an indicator because it is an absolute value; therefore, it cannot be used to evaluate the impact of $\mathrm{V} 2 \mathrm{G}$ functions on the SOC of the vehicle batteries [21]. Consequently, a second indicator is introduced as a relative value. This indicator is called the compensation vehicle factor (CVF), and it is defined as the ratio between the energy requested by the vehicle batteries during V2G compensation and the total storage capacity installed onboard, i.e.,

$$
\mathrm{CVF}=\frac{E_{\mathrm{EV} 2 G}}{E_{\mathrm{EV}}}
$$

In order to link the vehicle parameters with the events that have to be compensated for, it is useful to introduce (6) in (7); therefore, a first easy formulation of CVF that only considers the average values is obtained, i.e.,

$$
\mathrm{CVF}=\frac{P_{\mathrm{CS}} \cdot T_{s}}{E_{\mathrm{EV}}} .
$$

Equation (8) shows that the impact of the V2G functions on an EV is directly proportional to the charging power and the duration of the events that have to be compensated for, and it is inversely proportional to the storage capacity installed onboard. This means that, from the energy point of view, an EV is able to compensate for short network events, such as voltage sags or short interruptions, but it is not suitable for long interruptions that require high power.

A different case is the domestic application in which the CVF can be also acceptable for longer interruptions or local renewable plant integration because the requested power to supply home loads is low.

Considering that the primary mission for an EV is the transportation function, the storage batteries installed onboard have to be charged to keep the vehicle ready for use. Therefore, the CVF has to be as low as possible to not degrade the performance of the EV.

A more detailed formulation for the CVF can be obtained by considering the time integral of the instantaneous values in (8). This way, it is possible to introduce initial SOC $\mathrm{SOC}_{i}$ and the energy really drawn from the vehicle. Thus, a more suitable definition of the CVF that considers the real availability of the vehicle is given by

$$
\mathrm{CVF}=\frac{\int_{0}^{T_{r E}} P_{d \mathrm{EV}} \cdot d t}{E_{\mathrm{EV}} \cdot \mathrm{SOC}_{i}-\int_{0}^{T_{r E}} P_{d \mathrm{EV}} \cdot d t}
$$

where $P_{d \mathrm{EV}}$ is the power drawn time-by-time from the EV during time interval $\left(0-T_{r E}\right)$.

An acceptable value for the CVF could be maximum $10 \%$, i.e., only $10 \%$ of the stored energy could be used for $\mathrm{V} 2 \mathrm{G}$ services. This is because it is important to preserve the driving range of the vehicle only using a minimum part of the stored energy for the $\mathrm{V} 2 \mathrm{G}$ functions.

\section{PARKING EQUiPPED FOR RECHARGING EVs}

Mitchell et al. [22] presented the vehicles of the near future that have to be green, smart, connected, and fun to drive. Therefore, one of the most important characteristics of future vehicles is that they will be based on electric drives and wireless communication, rather than on petroleum, the internal combustion engine, and stand-alone operation. This is only possible if they are introduced in a city that is able to accommodate them, giving not only the parking but also the "feeding." Dynamically priced markets for electricity, road space, parking space, and shared-use vehicles must be introduced to provide optimum management of urban mobility and energy systems [23].

This paper proposes an intelligent interaction between EVs and the electric grid. The purpose is to allow the city to provide a distributed recharging for EVs and, at the same time, make this not only a sustainable solution to the electric grid but also advantageous. In fact, the onboard storage can be used to improve the stability of the network referring to an area close to the connection point.

For this reason, a dedicated electric model has been developed (see Fig. 3).

Referring to the scope of this paper, it is important to evaluate how many vehicles could be contemporaneously connected to the grid in the same area. This way, it is possible to estimate the quantity of power and energy available for compensating for voltage dips. In fact, the recharging stations can be used as compensation devices exploiting the onboard storage using different block diagrams, as proposed in [24]. 


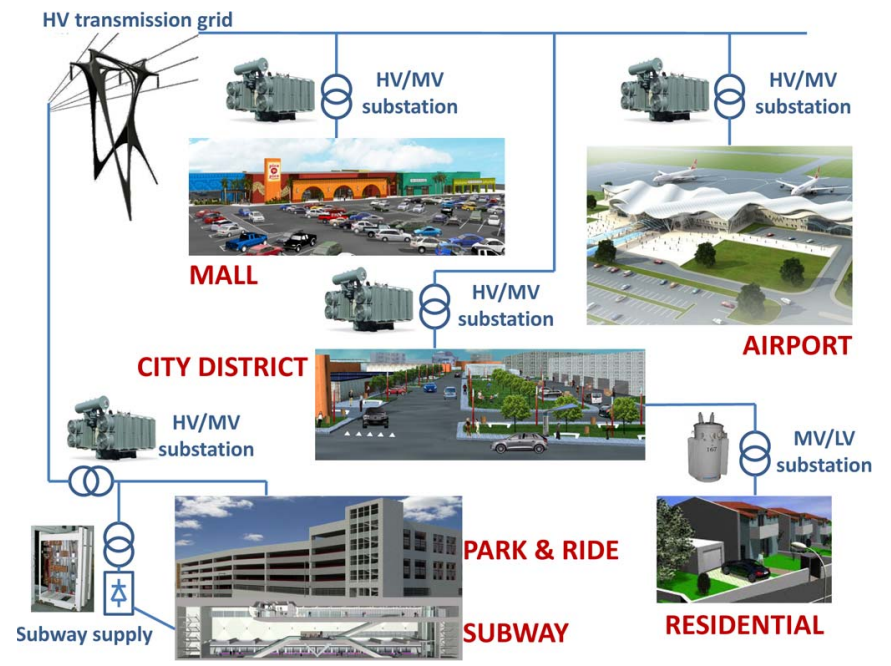

Fig. 3. Electric model of the different supplying areas.

In the following, possible scenarios, based on the average values presented in various real cases [25], [26], are hypothesized in order to perform a realistic energy and power analysis.

\section{A. Park and Ride}

An efficient city has to provide an integrated transportation system based on the interchanges between private and public transportation. The availability of parking facilities in the crown outside urban areas is an essential element in limiting car traffic coming from the hinterland. Obviously, these parking facilities have to be located nearby the main public transportation stations.

The data chosen as the hypothesis for this scenario are the following.

- The opening time of the park and ride: from 6 A.M. to 1 A.M., 7 days on 7 . Therefore, the maximum daily parking time for each vehicle is equal to $19 \mathrm{~h}$.

- The total capacity of the parking: 1000 vehicles.

- The percentage of places equipped with EV recharge stations: $10 \%$. This value is quite low because commuters normally arrive from the hinterland traveling for long distances; therefore, they have a proclivity for traditional vehicles.

- Probability to find electric cars $=70 \%$.

Considering the given assumptions, it is possible to hypothesize that the number of the vehicles that are simultaneously connected to the network during the opening time is equal to 70 .

\section{B. Mall Center Parking Areas}

Modern cities always have less little shops with preference to big areas where the customers can find all they need. Considering that malls are not located in the center of the city and that they are normally reached by car, they have to guarantee big parking areas.

The data chosen as the hypothesis for this scenario are the following.
- The opening time of the parking: from 8 A.M. to 10 P.M., 7 days on 7 . Therefore, the maximum daily parking time for each vehicle is equal to $14 \mathrm{~h}$.

- The total capacity of the parking: 1500 vehicles.

- The percentage of places equipped with EV recharge stations: $35 \%$. This value is higher than the value in the previous scenario because the customers identify the perfect moment for recharging their cars with the shopping time.

- Probability to find electric cars $=75 \%$.

Considering the given assumptions, it is possible to hypothesize that the number of the vehicles that are simultaneously connected to the network during the opening time is equal to 393 .

\section{Airport Parking Areas}

Airports can vary depending on its proximity with the biggest or smallest cities and on the presence of other minor airports.

The data chosen as the hypothesis for this scenario are the following.

- The opening time of the parking: $24 \mathrm{~h}, 7$ days on 7 . Therefore, the maximum daily parking time for each vehicle is equal to $24 \mathrm{~h}$.

- The total capacity of the parking: 4000 vehicles.

- The percentage of places equipped with EV recharge stations: $35 \%$. This value has been assumed to be higher, considering the incentives for the promotion of the EVs given to the rental companies.

- Probability to find electric cars $=80 \%$.

Considering the given assumptions, it is possible to hypothesize that the number of the vehicles that are simultaneously connected to the network is equal to 1120 .

\section{On-Street Recharge Stations}

This situation is more flexible and variable, depending on the recharge station position in the city. To statistically represent all possible scenarios, the data chosen as the hypothesis for this case are the following.

- The opening time of the recharge station: $24 \mathrm{~h}, 7$ days on 7. Therefore, the maximum daily parking time for each vehicle is equal to $24 \mathrm{~h}$.

- The number of recharging stations in a district: 30 .

- Probability to find electric cars $=75 \%$.

Considering the given assumptions, it is possible to hypothesize that the number of the vehicles that are simultaneously connected to the network is equal to 22 .

\section{E. Home Wallbox Chargers}

This scenario is based on a completely different hypothesis than the previous cases because the vehicle presence is related to the owner's routine.

Home charging is possible due to the suitable wallbox located in private parking areas.

More considerations on this application will be reported in the following section. 


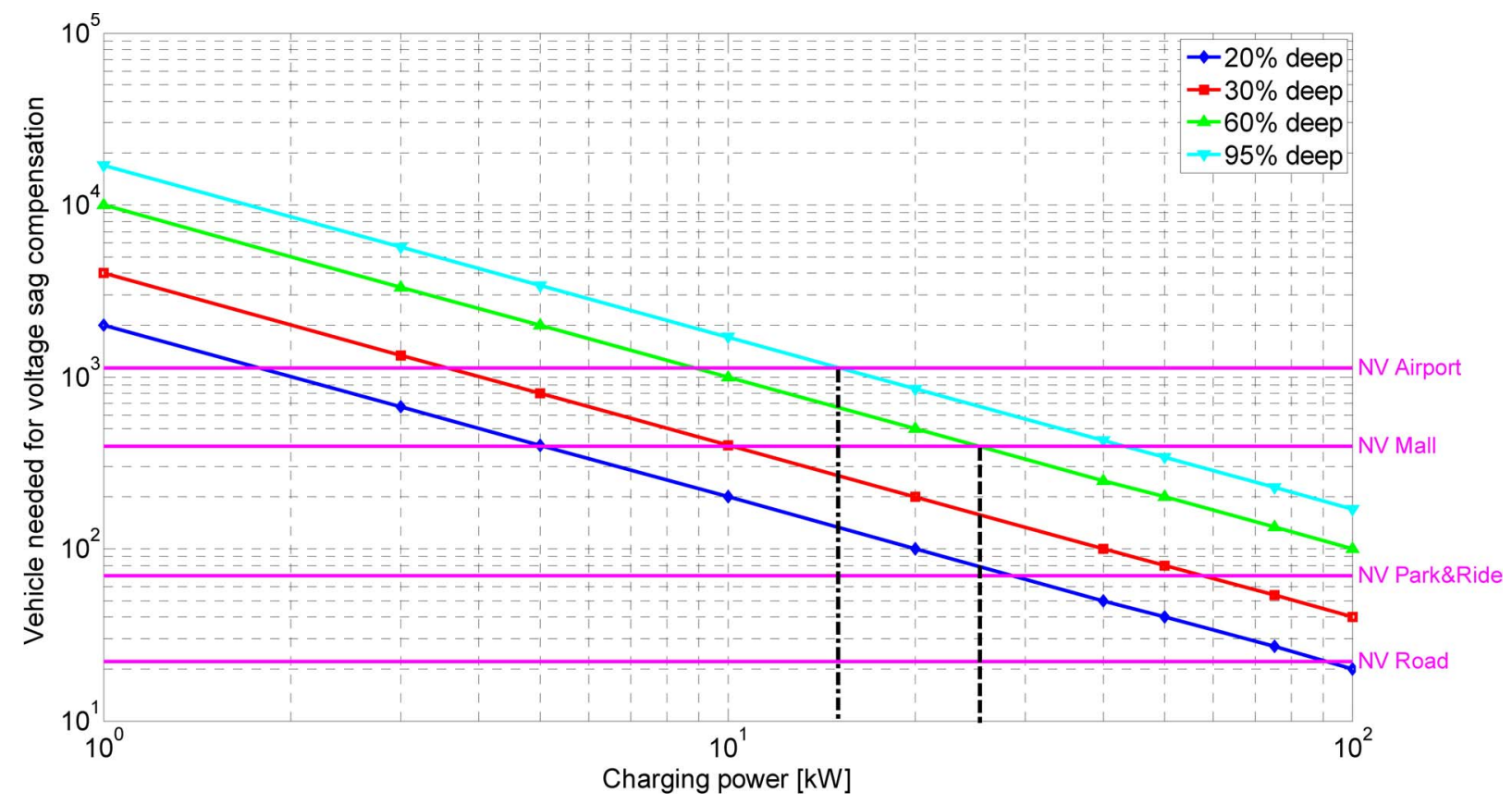

Fig. 4. Vehicles needed for voltage sag compensation as a function of the charging station power.

\section{CAse Studies}

This section presents an integrated analysis of all the previously introduced data. In fact, the most probable PQ events coming out from the analysis in Section II are considered and compared with the power and energy capability of the parking based on the different scenarios introduced in Section IV. The binding between network events and V2G solutions is possible due to the indexes proposed in Section III.

In the following, two different typologies of study cases will be presented:

1) publicly accessible recharging stations;

2) private recharging points.

In both cases, a deep analysis of the previously introduced indexes is developed in order to verify the V2G feasibility.

\section{A. Publicly Accessible Recharging Stations}

The recharging stations of public parking areas are connected to the primary district electric distribution network because they require high power values. Therefore, the V2G is suitable to compensate for short events (voltage sags, short interruptions, etc.) characterized by high power and low energy. As a consequence, the CVF is not so significant because, even in the worst case $\left(P_{\mathrm{CS}}=100 \mathrm{~kW}, T_{s}=60 \mathrm{~s}\right.$, and $\left.E_{\mathrm{EV}}=18 \mathrm{~kW} \cdot \mathrm{h}\right)$, it always remains lower than its maximum limit, assuring a good availability of the vehicle.

Instead, the $N V_{c}$ index determines the real feasibility of the V2G functions in relation to the chosen scenario.

Fig. 4 reports all the data in only one graph, presenting the vehicles needed for voltage sag compensation as a function of the charging station power (equal to the discharging power during a V2G function) and referring to the deepness of the sag and to the different hypothesized scenarios. This way, it is possible to introduce some considerations with regard to the feasibility analysis of the proposed solution.

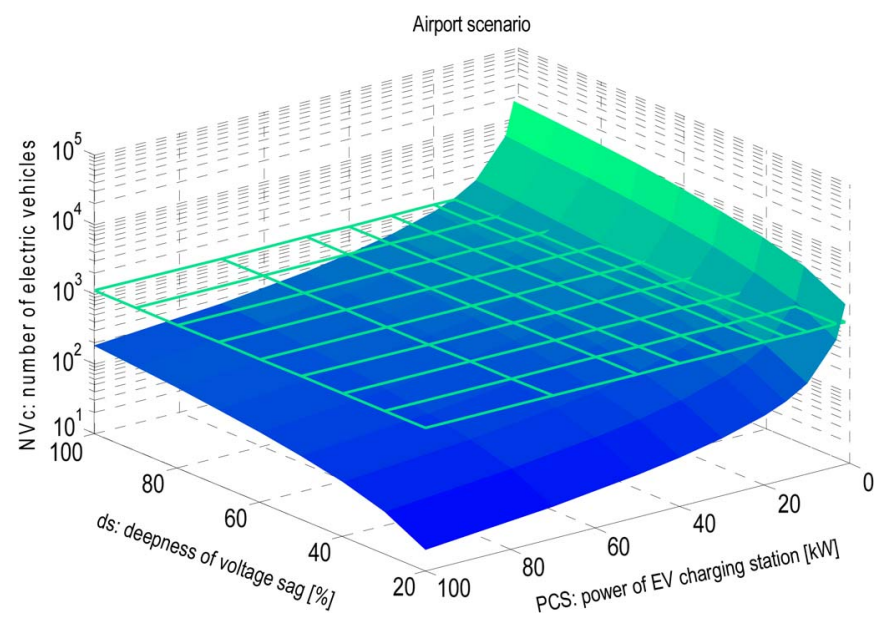

Fig. 5. Index representation for the airport scenario.

The boundary condition for each case has been assumed as a district power $P_{D}$ equal to $20 \mathrm{MW}$.

Fig. 4 shows that all the four representative scenarios introduced in Section IV could evaluate the introduction of the $\mathrm{V} 2 \mathrm{G}$ function to provide ancillary services to the network. The point is to understand if it is always convenient. The V2G functions have their maximum benefit only if inserted in a smart grid context that considers the possibility of islanding operation, in which a small portion of a grid is supplied from local generators and storage. Therefore, during a short interruption, it is possible that the connected vehicles supply the full load of the microgrid [27].

Surely, an airport parking area can be considered a good candidate to host charging points equipped with bidirectional devices. Fig. 5 demonstrates that the number of EVs contemporaneously connected in an airport parking should be enough to compensate for most of the voltage dips. In fact, it is possible to observe that the mesh representing the probable number of EVs 


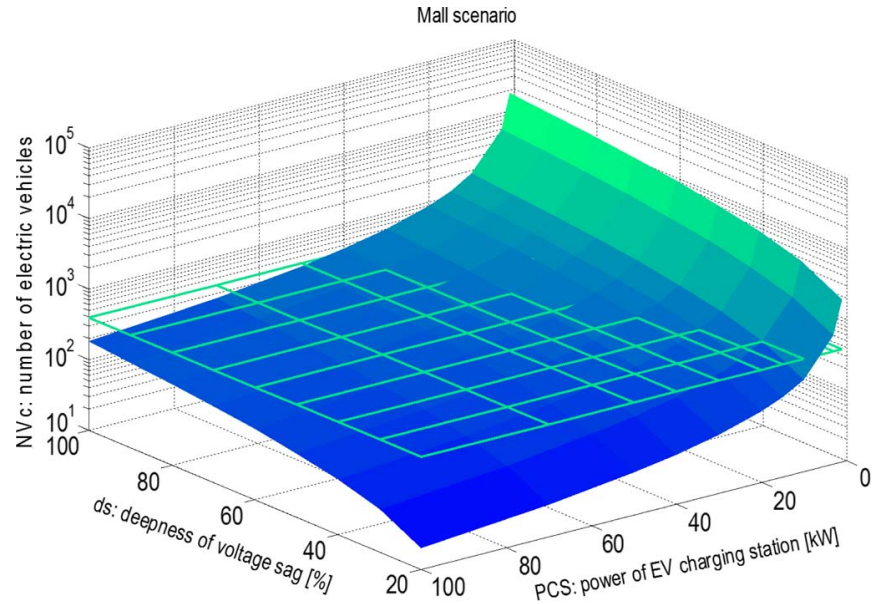

Fig. 6. Index representation for the mall scenario.

parked is quite totally above the filled surface obtained from (5). Therefore, it is possible to compensate for all the network events with a power station on the order of $15 \mathrm{~kW}$ (the dash-dot line in Fig. 4).

In addition, the parking of a medium-sized mall can be considered interesting for a V2G application; in fact, the mesh representing the probable number of EVs parked and reported in Fig. 6 is still sufficiently above the filled surface obtained from (5). In this case, it is convenient to only compensate for those voltage sags up to $60 \%$ of their deepness, in order to limit the power charging station close to $25 \mathrm{~kW}$ (the dash line in Fig. 4).

In both cases, the $\mathrm{V} 2 \mathrm{G}$ can be applied using reasonable power (inside the medium power range) for a charging station, which is currently installed all over the world.

On the contrary, the other two scenarios (the park and ride and the on-street recharge stations) as hypothesized here are not the right candidates for the proposed solution because they should require recharging stations with a too high power level, and this solution, although technically possible, will not be available in the near future. Fig. 4 shows, in fact, that the intersection between the vehicles needed for voltage sag compensation and the charging power is too on the right and is therefore far from a convenience point.

\section{B. Private Recharging Points}

Compared with the previous scenarios, this case is very different because the considerations are related to the energy problem instead of the power problem. In fact, supplying the vehicle with a private network, there is no problem on the power level (3-6 kW are available and adequate for the recharge process), but there are problems with regard to the energy. Considering that it is not acceptable to degrade the performance (the driving range) of the vehicle, it is necessary to limit the maximum energy that can be drawn for compensation.

Consequently, the variable to consider is no longer the number of vehicles but the service typology, such as long interruption compensation, renewable sources' mitigation, or power peak shaving. Therefore, the representative index is the $\mathrm{CVF}$ and is no longer $N V_{c}$ because the power requested is low and, according to (9), the CVF can be also acceptable for longer compensation. In fact, the integral in (9) also remains at a

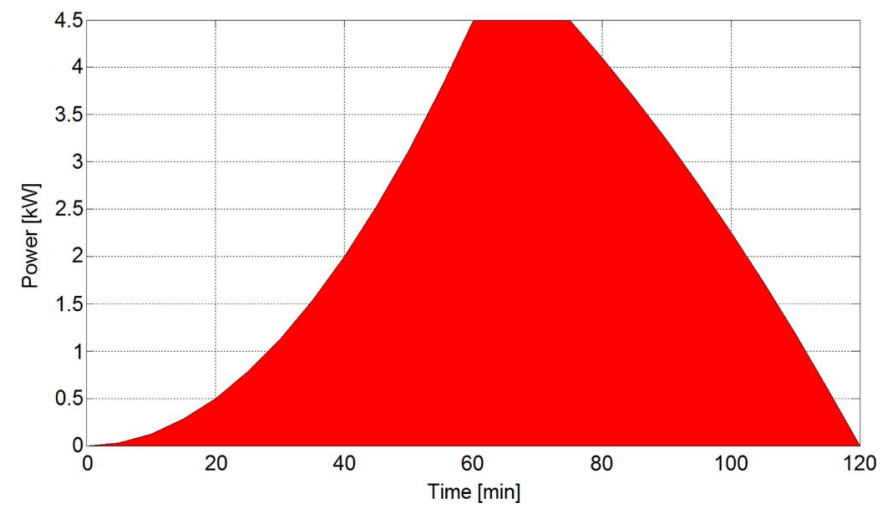

Fig. 7. Typical home load diagram.

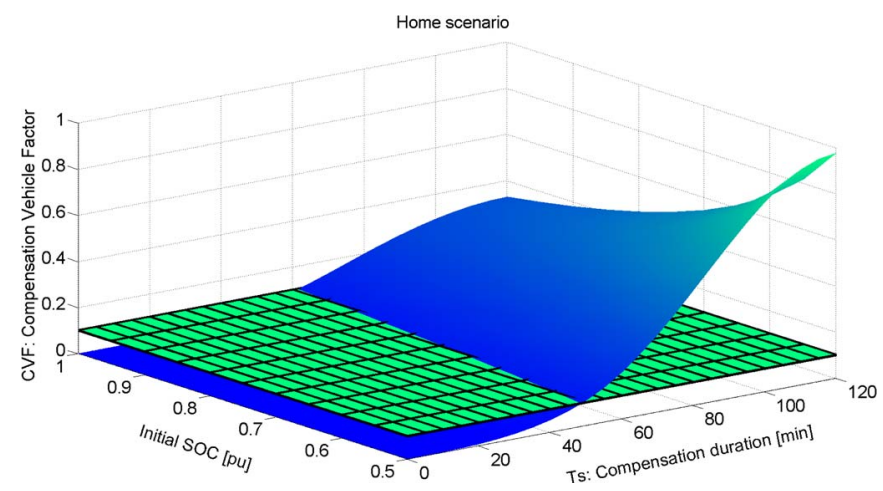

Fig. 8. Representative index representation for the home charging scenario.

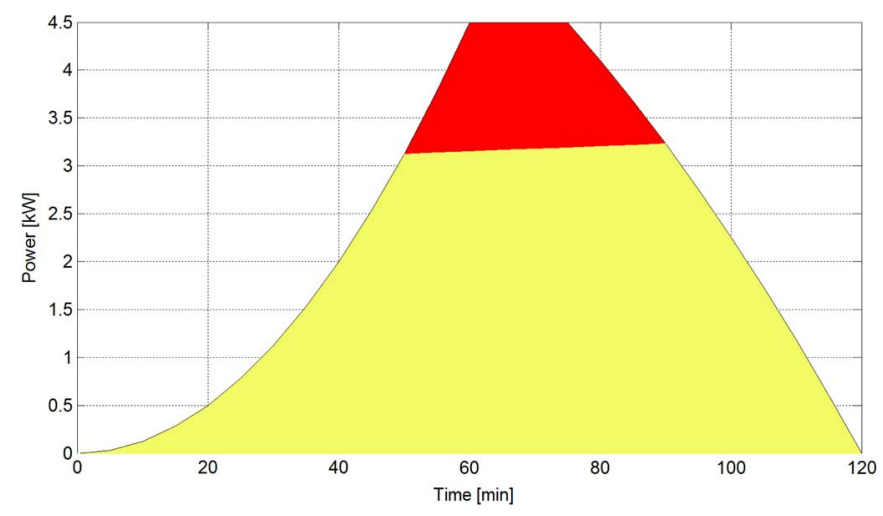

Fig. 9. Typical home load diagram, where the dark area corresponds to the energy amount needed from the batteries.

reasonable value for longer compensation times $\left(T_{r E}\right)$ because the required $P_{d \mathrm{EV}}$ is low due to the low power rate of the domestic appliances.

Considering a load diagram that includes the peak power (see Fig. 7), in case of a long interruption, the EV has to deliver an energy amount that is equal to the area under the diagram curve.

However, the EV is not able to sustain such amount of energy all the time. In fact, as shown in Fig. 8, the CVF index exceeds the maximum admitted value (10\%) for most of the time, particularly if the vehicle is not fully charged.

For this scenario, the power peak shaving can be a more interesting service that a vehicle can give for home energy management. In this case, the energy requested from the vehicle is much lower, as depicted in Fig. 9, where the energy amount needed from the batteries corresponds to the dark area. 


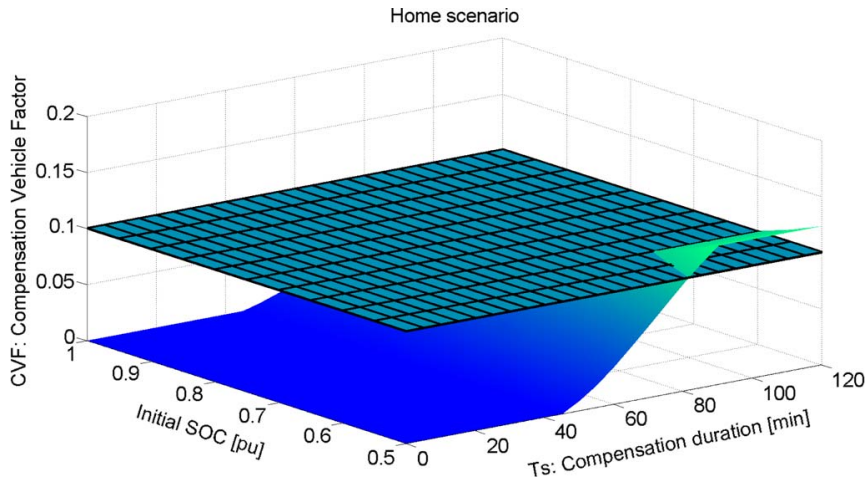

Fig. 10. Representative index representation for the peak shaving in the home charging scenario.

As shown in Fig. 10, the CVF index is always quite acceptable all the time. Some problems could arise if the initial SOC is really low.

\section{CONCLUSION}

In this paper, a deep analysis of $\mathrm{V} 2 \mathrm{G}$ services has been presented, focusing on real scenarios that could happen in the near future. In particular, starting from a survey of the electric network disturbances carried out on the Italian distribution grid in 2012, different representative cases have been hypothesized, introducing significant indexes that give the feasibility of the V2G services.

The study presented in this paper has shown that EVs could only improve the PQ of the network where it is probable to have many cars contemporarily connected, which is the case for an airport or a mall parking. The other cases analyzed are not candidates for $\mathrm{V} 2 \mathrm{G}$ services because they do not have a sufficient number of vehicles connected. This means that, in these cases, it is not convenient to install bidirectional charging stations with sophisticated communication systems.

A particular case regards home charging, in which $\mathrm{V} 2 \mathrm{G}$ is useful to compensate for a longer interruption on the order of $20 \mathrm{~min}$ or to provide the power peak shaving.

\section{REFERENCES}

[1] H. Kanchev, F. Di Lu, V. Colas, and B. Lazarov, "Energy management and operational planning of a microgrid with a PV-based active generator for smart grid applications," IEEE Trans. Ind. Electron., vol. 58, no. 10, pp. 4583-4592, Oct. 2011.

[2] S. Paoletti et al., "Load forecasting for active distribution networks," in Proc. IEEE PES Int. Conf. Exhib. ISGT Europe, 2011, pp. 1-6.

[3] M. Brenna, F. Foiadelli, P. Petroni, G. Sapienza, and D. Zaninelli, "Distributed generation regulation for intentional islanding in smart grids," in Proc. IEEE PES Innov. Smart Grid Technol., 2012, pp. 1-6.

[4] M. H. J. Bollen, N. Etherden, K. Yang, and G. W. Chang, "Continuity of supply and voltage quality in the electricity network of the future," in Proc. IEEE 15th ICHQP, 2012, pp. 375-377.

[5] J. C. Gomez, J. Vaschetti, C. Coyos, and C. Ibarlucea, "Distributed generation: Impact on protections and power quality," IEEE Latin Amer. Trans., vol. 11, no. 1, pp. 460-465, Feb. 2013.

[6] "Proposal for a regulation to define the modalities for reaching the 2020 target for reducing $\mathrm{CO} 2$ emissions from new passenger cars," Brussels, Belgium, COM/2012/393, Nov. 7, 2012.

[7] "Communication from the commission to the council and the European Parliament 6 results of the review of the community strategy to reduce $\mathrm{CO} 2$ emissions from passenger cars and light-commercial vehicles," Brussels, Belgium, Nov. 2, 2007.
[8] "Commission regulation (EU) no. 397/2013 amending regulation (EC) no. 443/2009 as regards the monitoring of $\mathrm{CO} 2$ emissions from new passenger cars," Brussels, Belgium, Apr. 30, 2013.

[9] A. Izadian, N. Girrens, and P. Khayyer, "Renewable energy policies: A brief review of the latest U.S. and E.U. policies," IEEE Ind. Electron. Mag., vol. 7, no. 3, pp. 21-34, Sep. 2013.

[10] M. Yilmaz and P. T. Krein, "Review of the impact of vehicle-to-grid technologies on distribution systems and utility interfaces," IEEE Trans. Power Electron., vol. 28, no. 12, pp. 5673-5689, Dec. 2013.

[11] M. Brenna, F. Foiadelli, and D. Zaninelli, "Power and energy estimation for plug-in electric vehicles recharge in metropolitan area," in Proc. Int. Conf. EPQU, 2011, pp. 65-70.

[12] S. S. Hosseini, A. Badri, and M. Parvania, "The plug-in electric vehicles for power system applications: The Vehicle to Grid (V2G) concept," in Proc. IEEE Int. Energy Conf. Exhib., 2012, pp. 1101-1106.

[13] J. R. Pillai and B. Bak-Jensen, "Integration of vehicle-to-grid in the Western Danish power system," IEEE Trans. Sustainable Energy, vol. 2, no. 1, pp. 12-19, Jan. 2011.

[14] U. K. Madawala and D. J. Thrimawithana, "A bidirectional inductive power interface for electric vehicles in V2G systems," IEEE Trans. Ind. Electron., vol. 58, no. 10, pp. 4789-4796, Oct. 2011.

[15] D. Wu, K. T. Chau, C. Liu, S. Gao, and F. Li, "Transient stability analysis of SMES for smart grid with vehicle-to-grid operation," IEEE Trans. Appl. Supercond., vol. 22, no. 3, p. 5701105, Jun. 2012.

[16] The Italian System for Power Quality Monitoring of MV Distribution Networks. [Online]. Available: http://queen.rse-web.it/eng/buchi1.aspx

[17] M. Brenna et al., "Automatic distributed voltage control algorithm in smart grids applications," IEEE Trans. Smart Grid, vol. 4, no. 2, pp. $877-$ 885, Jun. 2013.

[18] Voltage Characteristics of Electricity Supplied by Public Electricity Networks, EN 50160, 2010.

[19] Electromagnetic Compatibility (EMC) - Part 4-11: Testing and Measurement Techniques - Voltage Dips, Short Interruptions and Voltage Variations Immunity Tests, Eur. Std. EN 61000-4-11, 2004.

[20] Electromagnetic Compatibility (EMC) - Part 4-34: Testing and Measurement Techniques - Voltage Dips, Short Interruptions and Voltage Variations Immunity Tests for Equipment With Mains Current More than $16 \mathrm{~A}$ per Phase, Eur. Std. EN 61000-4-34, 2009.

[21] L. Ran, W. Junfeng, W. Haiying, and L. Gechen, "Prediction of state of charge of lithium-ion rechargeable battery with electrochemical impedance spectroscopy theory," in Proc. 5th IEEE ICIEA, 2010, pp. 684-688.

[22] W. Mitchell, C. Borroni-Bird, and L. Burns, Reinventing the Automobile: Personal Urban Mobility for the 21st Century, 1st ed. Cambridge, MA, USA: MIT Press, 2010.

[23] M. Brenna et al., "Challenges in energy systems for the smart-cities of the future," in Proc. IEEE Int. Energy Conf. Exhib., 2012, pp. 755-762.

[24] M. Brenna, F. Foiadelli, and D. Zaninelli, "Voltage sags compensation through a DVR supplied by V2G vehicles charging stations," in Proc. 4th IEEE/PES ISGT Europe, 2013, pp. 1-5.

[25] CESifo Working Paper Series No. 4416 R. J. Arnott, On the optimal target curbside parking occupancy rate, Sep. 30 2013, 30, CESifo Working Paper Series No. 4416.

[26] M. Caliskan, A. Barthels, B. Scheuermann, and M. Mauve, "Predicting parking lot occupancy in vehicular ad hoc networks," in Proc. IEEE 65th Veh. Technol. Conf. Spring, 2007, pp. 277-281.

[27] C. Gouveia, C. Moreira, J. Lopes, D. Varajao, and R. Araujo, "Microgrid service restoration: The role of plugged-in electric vehicles," IEEE Ind. Electron. Mag., vol. 7, no. 4, pp. 26-41, Dec. 2013. 